\title{
Use of Arbuscular Mycorrhizal Fungi for Vegetable Crops
}

Bandi Arpitha Shankar

Acharya N G Ranga Agricultural University, Tirupati-517502, Andhra Pradesh

\begin{abstract}
AMF (Arbuscular Mychorhizal Fungi) are very well known due to their importance in promoting growth and developments of plants especially vegetables. These fungi can be grown easily, stored and multiplied with simple means, also the application of these fungi is generally on the layer of the soil or near the roots in the inner layers of the soils. The growth of the amf fungi is very easy and they are highly adjustable to any soil and environmental conditions. In this review our main focus is on the use of amf for production of vegetables and also the effect of amf against insects and pests. The amf is known to reduce several symptoms caused by different insect pests and also plant diseases thereby promoting healthy growth of the plants. Also use of this amf will increase the uptake of nutrient from the soils through symbiotic relationships between plants and fungi. The uptake of important minerals which are drawn from deeper layers of soils is observed with the help pf amf. This study reveals the benefits of the use of amf under severe disease and pest incidences thereby known as an alternate for harmful chemical pesticides and fungicides.
\end{abstract}

Keywords: AMF, Vegetable production, plant pests, plant diseases

\section{Introduction}

Vegetables are considered as important source of nutrition, dietary fiber and many other health benefits. Vegetables are a part of every meal all over the world. Vegetables are mixed with several other eatables to make a new dish. These vegetables are eaten not only by humans but also by some herbivore animals. Vegetables are eaten raw sometimes half boiled and completely cooked. In some dishes vegetables are deep fried to increase the taste. In India vegetables are eaten along with rice, roti, parathas and dosa sometimes, whereas in many other countries they are added afresh to the bread making it very tasty. These breads sometimes referred to as sand-which, pizzas and sub. Several times vegetables are mixed with meat to enhance the taste and quantity of the food served [1].

It is well known and proved that the people who consume more vegetables are known to be safe with less risks of certain harmful diseases like cancers, heart strokes etc. These vegetables are very useful in minimizing the calorie intake by providing several vitamins and minerals. Now a days a lot of people switched to vegetarian food called veganism due to the increasing importance of vegetables in our day to day lives [2]. It is always known that Health is Weatlh , and that is possible with the use of vegetables in our day to day lives. It is proven that the vegetables provide both mental health and physical health. In some reviews improper mental health is due to improper food habits. Such experiences paved way to draw possible links between use of vegetables and positive mental health by reducing the risks of certain syndromes in both children and adults. Also certain health benefits are listed by important central agencies like Improved bone health, Weight balance, Proper vision, High antioxidant properties, skin and hair health etc.[3]. 
Many nutrients are available for different vegetables like proteins from spinach, broccoli, sprouts, peas, legumes etc. Whereas zinc and iron is obtained from spinach, hemp, peas and beans which are veery useful in creating responses for the increase of dopamine which is very helpful in reducing the risks of syndromes. Also, vitamins and minerals are obtained from broccoli having high calcium, cabbage and cauliflower provides best vitamin $\mathrm{C}$, whereas lettuce provides vitamin B and spinach provides vitamin K [4]. Due to the above important nutrition benefits, vegetables are considered as the most important source of health. Also, the cultivation of vegetables is very easy and it takes very less time compared to cereal production. They require very less water and fertilizers to grow. These vegetables can also be grown in homes under kitchen garden. With a very less input in cultivation maximum benefits is obtained in vegetable production [5].

But it is observed that there are maximum yield losses due to pests and diseases and certain abiotic stress. Coping up these stresses is sometimes difficult to the plant depending upon the soil and environmental conditions. The yield of the plant, size, tase etc. are greatly affected due to these stresses. Certain pests are known to invade and the crops through roots and enter the fruits as borers damaging the entire crop. Also, certain disease spread easily and damage the leaf area thereby reducing the photosynthesis and ultimately leading to stunted growth of the plants. To this problem certain temporary solutions came up but are less successfully and poising greater damage to the soil and human health [6]. There are several fungicides and pesticides which are used to treat diseases and pests but prolonged use of these harmful chemicals spoils the soil health. Also, these harmful chemicals have hygroscopic activity in which they enter into the plant system by vacuole or any cell opening from the epidermis. This is one of the reasons for causing cancers in humans because these chemicals contain many free radicals and are very dangerous. Due to this reason use of certain microbes like bacteria and fungi individually or together is very advantageous as they have only positive impact on the soil but not any threat [7].

Certain fungal species like AMF (Arbuscular Mycorrhizal fungi) are very well known and proven fungal species in improving the soil and plant conditions under biotic and abiotic stresses. These fungi are known as VAM (Vascular Arbuscular Mycorrhizal) fungi belonging to Glomeromycota class and are found at the base of higher trees. These fungi are known to be well adapted to terrestrial living compared to other fungi. This group of fungi are well known to develop symbiotic relationship with the plant so that the frequency of the movement of nutrients and water from the soil to the plants are increased at a great level. These AMF are found to be in the regions or soil conditions where there is continuous incidence of biotic and abiotic stresses. This AMF is a major class which involves molds, mushrooms and yeasts. All these are involved in nutrient enhancement whereas molds are mostly utilized for this purpose in different combinations [8].

It was well understood that the use of these fungi is quite useful in the growth and development of the plants due to easy access of nutrients required for the plant growth. Also, the damage caused by certain diseases due to some pathogens can be reduced with the use of these AMF. Recently certain studies proved that the use of this AMF is beneficial for treating the plants infested with certain pests, not by directly killing the pests [9].

As vegetables are very important for our living due to our daily dependance protecting them from harmful diseases and pests also by increasing their yield is very much beneficial in 
meeting the needs. Almost all the vegetable plants are known to host AMF thereby to improve their nutrient content and become tolerant to several stresses, by increasing their biomass content and photosynthetic ability. Several families like Amaryllidaceae, Fabaceae, Cucurbitaceae, Asteraceae etc. show their dependency towards AMF for these added benefits in the growth and development of the crop [10]. These AMF are not only helpful to the plant but also very much helpful to the soil by increasing the nutrient content in the soil. Also, these soils are known to have high porosity compared to non-mycorrhizal soils. Whereas, the appearance of the soils, soil density, soil structure and texture are known to change in a positive way due to the use of AMF bioinoculants [11]. Also, the plants that are inoculated are known to produce best fruits and good foliage with high nutritional value which is healthy not only for humans but also herbivores.

These fungi that are associated with the plants provide thnitrogen, phosphorus, nutrients, water etc. to the plants and in turn they get the carbon dioxide required for their growth and survival. In our review the importance of AMF on the growth of vegetable crops along with their management on pests and diseases is investigated [12]. Different fungal combinations or sometimes fungi and bacteria are together used to promote symbiotic relationships with the plants and the soil [13]. The process of production of the bioinoculants in large scale their combinations, usage in vegetables and their help in plants that are infected with diseases and pests are studied.

\section{Mycorrhizal production and multiplication:}

As well known the AMF has several advantages by improving, maintaining and balancing the supply of the nutrients. These fungi are known to draw all the nutrients from the soil and translocate these nutrients to the plants which include N, P, k, P, S and several others [14]. In certain soils that are not properly maintained or well drained AMF is very useful. Also certain soils lacking some essential nutrients or soils that re spoilt by the regular use of chemicals can be maintained by the use of these bio inoculants. These bioinoculants are very helpful as they draw the nutrients by extending their hyphae to a maximum extent i.e., deeper into the soils [15].

The production of these bioinoculants is very important and require special techniques and machinery. these bioinoculants can be obtained from normal soil, treated soils from the plants or from the roots [16].

\section{Soil inoculum:}

The inoculum is obtained rom normal soil collected from a healthy field under well drained and maintained conditions. This may contain weeds, soil debris, peat, unwanted materials, other bacterial agents and fungal inoculum. All the weeds, soil debris are to be carefully removed before the production of the AMF. The isolation of AMF fungi form other soil debris is difficult because it is in mixed form and very much time taking, also the viability of the fungal spores is not very accurate due the reduced viability and tendency of the spores. The process of isolation of spores from normal soils and produced elsewhere is called trap culture, which sometimes increases the viability of the spores if nutrients are properly provided[17].

\section{Crude inoculum:}


The selection of soils having known inoculum, which is previously inoculated for the production of the fungi is called crude inoculum. These spores are known to have high viability and show proper multiplication. These soils may contain known fungal hyphae, spores etc. including the roots of the particular plant to which the AMF was inoculated previously. The hyphae and spores are separated from other infected propagules by a process called decanting, and used for mass production of the fungi. Therefore, the soil obtained contain different fungal propagules which is very useful [18].

\section{Root inoculum:}

The fungal propagules can be obtained form the infected root, which is previously infected by AMF. These roots contain highly viable and active fungal spores and hyphae attached. This inoculum obtained from the roots can serve as a best source for mass production of fungi [19].

The mass production of the inoculum depends upon certain factors which play a major role in providing high quality fungal spores that are,

- Type of the culture,

- Nature of the nurse plant,

- Media and

- Growth conditions.

The production of spores and hyphae in a proper way and in high quantity is very much important to prepare biofertilizers, where all the above factors play a key role and effect the production.

\section{Process of amf production:}

\section{Isolation of spores:}

The spores are isolated from any of the above source and are separated carefully by sieving method.

\section{Physical habitat:}

The media used for the production of AMF includes sand and soil mixture where the sand is usually silica sand because the silica sand has a property of drying up quickly if no irrigation which can be counted as an advantage to arrest the growth of other microbes immediately after the harvest of the AMF. Certain plant species belonging to the families that are highly responsive to AMF are selected and are used for the production of the fungi. These plants are allowed to grow along with the addition of the AMF spores on the soil surface near the roots. These soils are previously heated to kill all the other microbes and are separated rom all unwanted materials. The moisture of the soil is to be maintained and the cultivation practices are to be followed as usual. To attain maximum multiplication of the spores the growth of the plants in green house is generally practiced due to the availability of controlled environmental conditions [20].

\section{Type of the container:}

Containers are selected in a way in which they are easy to handle, break after the process and lightly opaque to reduce the light penetration. Usually black plastic bags or pots made up of 
clay and concrete are selected for the growth of the inoculum so that they maintain controlled conditions and their handling is also easy [21].

\section{Starter culture:}

The inoculum should be selected from a trusted source, where the pure inoculum is available and can be easily applied on the soil without any other microbial growth. The culture should be in pure form so that the production of AMF will be more than double per plant[22] .

\section{Nurse plants:}

Those plants that are used to produce the inoculum are to be selected carefully and are to be adapted to the growing conditioned. These plants should have optimum growth cycle preferably short duration and needs to grow real fast. These plants should be capable of withstanding any pests and diseases up to a maximum level and should posses a positive symbiotic relation with the fungi[23].

\section{Nutrient availability:}

The pots in which the inoculum is produced should be provided with proper nutrients and water. The quantity of the nutrients are to be checked and applied to the soil time to time so that it will be an added advantage to the growth of the fungus[24].

\section{Duration:}

In general the production of the fungus is maximum within 13-14 weeks of application. The growth observed here where the production reaches the maximum at the end of $14^{\text {th }}$ week and gradually retards indicating the change of the environment[25]. This stage is ideal to separate the fungal inoculum produced and allowed for mass multiplication, where the fungus increases in quantity under controlled conditions and continuous supply of nutrients in different cultures[26].

\section{Mass multiplication:}

Three major systems are well adapted for the multiplication of AMF, these methods are quick, easy and less laborious.

\section{Production system with substrate:}

This is a classical method in which the specific fungal spores are allowed to grow in specific pots or containers with large raised beds with sand or soil. The system was under controlled conditions of temperature and nutrition. The plant parts along with the inoculum can be removed easily by sieving. Also spores of fungi can be separated by decanting method. Thus these beds that are occupied with thick fungal growth are harvested at a time after complete growth of the fungus. This system is also suitable for mixed inoculums as well[27].

\section{Production system without substrate:}

This is a system where the nutrient flow is continuous and not directly added to the growing beds. The nutrients are aerated by a special pump in order to avoid nutrient and oxygen exhaustion in the growing beds. Due to this proper supply of nutrients time to time the nutrient depravation losses are minimized ion the region of fungal growth. Continuous supply of 
nutrients is not seen in this system and there may be less multiplication of inoculum. A particular solid substrate like soil and nutrients is not needed in this system[28].

\section{In-vitro system:}

In a bioreactor the roots along with the fungal inoculum is added along with the sufficient nutrients for fungal multiplication. These bioreactors can be continuous and discontinuous depending upon the supply of nutrients, gases and water. In certain bioreactors the nutrients, inoculum and substrates are added in a batch and are harvested altogether. But in some cultures nutrients, gases are continuously supplied to the bioreactors containing fungal inoculum and the freshly multiplied inoculum is collected along with the exhausted nutrients to reduce the risk of waste build up, this is observed in continuous bioreactors[29].

This process of in vitro multiplication of fungus is very much beneficial and highly productive compared to other systems and mass multiplication of mixed inoculums[30].

\section{Arbuscular Mycorrhizal Fungi and vegetable production}

As known the vegetables play a major role in our day to day lives as a main source of food and nutrition. Their short life cycle restrict their dependence on the chemical fertilizers in general. In few cases the incidence of pests and diseases if severe would create a situation for the dependence on chemical fertilizers, pesticides and insecticides[31]. The prolonged use of these pesticides and chemicals would effect the soil conditions and the crop growth. The availability of nutrients in the soil and the growth of useful microbes is gradually decreased due to harmful chemicals[32]. Along with the soil the crop draws all the chemicals present in the soils and have a negative effect on human health due to their hygroscopic nature i.e., pesticide content in the consumable part of the vegetable. To minimise these losses there is no any practical way but to constrict the use of these chemicals. But this is not the solution for all the problems caused by pests and diseases. Recently certain reviews and research was done in the use of the AMF against biotic and abiotic stress and ultimately the production of vegetables[33].

These AMF bioinoculants are known to have major useful effects on the growth and yield of vegetable crops. The use of these fungal bioinoculants not only help in the growth of the plant but also help the plant against certain stresses[34]. These AMF bioinoculants develop a certain type of symbiotic relationship with the host plants and facilitate their growth under stressful conditions by a series of events between the plant, fungus and soil. These events may include the enhancement of the photosynthetic rate of the plant, increase in the vascular connections within the plant and with the fungi also useful gaseous exchanges between the plants and the soil[35].

These symbiotic relationship between the fungus and the plants is not only beneficial to the plant and soil but also very much beneficial to the fungus itself[36]. The fungal bioinoculants are able to increase the nutrient content in the plants, water absorption and mineral contents which effect the growth of the plants by providing maximum yields[37]. Also, to this in exchange the fungus is able to increase its population by maximum reproduction in association with the plant which would be the suitable source for the fungal nourishment. By this means both the host and the bioinoculants are at maximum advantage[38].

Many plants can host the AMF fungi, but few plants are susceptible to the microbial growth and tends to show negative impact on their growth. Several plants like onions, garlic, carrots, 
tomatoes and herbs show high positivity with the use of AMF inoculants even though they are grown in pots or trays[39]. Also, certain annual flower beds like ornamental grasses, aloe etc are highly responsive to the fungal growth[40]. It was observed in few reviews that the use of AMF on the growing plants like Ipomea and Maple helped in increasing the leaf size and growth of the plants respectively[41].

The AMF is added to the soil in different ways depending upon the purpose or use , usually sprinkled on the seed in the soil to obtain good growth and quality of the plants. In few cases this is added to the soil near the roots for maximum plant growth and yield[42].

Table 1: Examples of the role of AMF in crop production

\begin{tabular}{|l|l|l|}
\hline CROP & SPECIES & RESULTS \\
\hline Rice & AMF & Increased vegetative growth \\
\hline Tomato & Glomus mosae & Increased yield of the plant \\
\hline Soybean & AMF & Increased growth of the plant \\
\hline Peas & Gigaspora gigantia & Size of the leaf and pods \\
\hline Onion & AMF & Seedling establishment \\
\hline Clover & G. intraradices & Increases shoot dry weight \\
\hline Canola & G. versiforme & Promotes shoot growth \\
\hline Citrus & G. versiforme & Drought stress tolerance \\
\hline Sunflower & U. mosseae & Drought stress tolerance \\
\hline Soybean & H. intraradices & Drought stress tolerance \\
\hline
\end{tabular}

There are several advantages in using the AMF in crop improvement and production where the growth of the crop and yield were known to be maximum in case of rice, tomato and soybean, whereas the seedling establishment is good without drooping of the plants in onions. In certain legumes AMF increase the length of the leaf and pods size and number as they are the main parts of consumption. Hence it was very well understood that the use of AMF in crop production was very beneficial to the plant, soil and the fungi itself.

\section{Arbuscular Mycorrhizal Fungi and vegetable disease control}

AMF is well known to protect the vegetables and other plants from severe stresses and especially certain diseases. These bioinoculants are well known to reduce the effect of soil borne diseases on the plants[43]. It was well known that the fungi allow the plants to grow well under several serious diseases. The series of events occurring between the plants and the microbes would allow the intake of the nutrients from the soil into the plants so that the plants do not die[44].

The bioinoculants are applied to the surface of the soil in some vegetables, but in few cases these are added in the inner layer of the soil very near to the roots. In some fruits the seeds are well dipped in the bioinoculants as it covers the entire seed as a prote3ctive agent before the onset of any disease[45]. These bioinoculants draw the necessary and helpful nutrients from the soil and promote vascular connections between themselves and the effected plant. The bioinoculants not only draw sufficient nutrients but also permits additional moisture in the plants and the soil thereby the disease condition does not become very severe[46]. 
In some plants like cucurbits these bioinoculants are known to increase seedling survival rate of the seedling which is effected by certain diseases. In case of soy bean root rot disease AMF is known to play a major role in protecting the plants by reducing the severity of the disease[47]. Also in certain wilts and rots AMF protects the plants by drawing the necessary nutrients and substitute them. In some cases AMF is known to maintain levels of certain important plant nutrients that are lost due to diseases, which include $\mathrm{Zn}, \mathrm{Cu}$ and $\mathrm{Fe}$. These fungi draw these nutrients from the deeper layers of the soil and make them available to the plants by their connections[48].

Very importantly the plant structure, yield and roots are soil due to the effect of diseases, with the help of AMF these losses can be reduced to a greater level where the leaves of some plants are known to grow well and the leaf area was increased even after the effect of diseases[49]. Also in some diseases rots in the stems are a common symptom but due to the addition of AMF to the soils the stems of the plants remain good and not very much spoil or wilted[50]. Most importantly the roots of the plants effected by the soil borne pathogens are known to rot and show some disfiguration the addition of AMF to the plants inside the soils near the rooted areas protected the roots up to maximum level where the roots grow well and are healthy without any symptoms of rot[51]. It was also observed that the roots of the plants supplied with AMF were proven to show maximum increase in their height, these roots dig deep into the soils. This is very important and beneficial event caused by the use of AMF because the roots that are deep in the soils allow the roots to draw more nutrients and water from the deeper layers of the soils. In some cases the deeper roots are very beneficial as they escape some diseases caused by some soil borne pathogens[52].

It was also observed that the treatment of the roots with AMF helps the plants by restricting the entry of nematodes into the plants through the roots which is the main entry point of several nematodes. In some crops like tomatoes the entry pf nematodes are restricted to a maximum level also the reproduction of these nematodes is greatly restricted by the addition of AMF near the roots[53].

The enhancement of the nutrients and the enzymatic activity of the soil is known to increase along with the change in the root exudates by producing which are highly beneficial was also observed. All the important factors and benefits obtained by the use of AMF makes it more popular than the use of harmful chemicals[54]. Although the availability and storage if these bioinoculants area difficult their effects are known to last. AMF bioinoculants does not make the plants healthy even after the disease onset but protect the plants from maximum damage sometimes by increasing the growth and yields of the plants which make it a best option for use compared to harmful pesticides effecting the plant health, soil health and human health[55].

Table 2: Use of amf against different diseases

\begin{tabular}{|l|l|l|}
\hline CROP & AMF SPS. & PROTECT AGAINST \\
\hline Tomato & Glomus mosae & Root knot nematode \\
\hline Asparagus & Gigaspora margarita & Fusarium wilt \\
\hline Tomato & Glomus monosporum & Stunt disease \\
\hline Cucumber & Glomus etunicatum & Root rot and stunt disease \\
\hline Pepper & Glomus aggregatum & Root rot \\
\hline Cow pea & G.gigantea & Charcol rot \\
\hline
\end{tabular}




\begin{tabular}{|l|l|l|}
\hline Trifolium & G. mosseae & Leaf blotch \\
\hline Orange & F.mosseae & Leaf curl \\
\hline
\end{tabular}

Several crop species are known to tolerate severe diseases with the use of amf under required quantities. Several plants are known to tolerate the effects caused by various diseases like wilts, root rots, stunt diseases etc. The use of amf fungi was maximum in case of tomato which is highly susceptible for several diseases.

\section{Arbuscular Mycorrhizal Fungi and vegetable insect control}

Several vegetable crops are known to be infested by different insects as pests and are prone to severe damage[56]. These plants show some defences directly or indirectly up to a certain level but not under severe conditions. This pest problem is seen even though several management practices are taken. The yield of the plants is gradually decreased with the pest incidence[57]. Several yield losses are observed in case of pest damage effecting the lives of several farmers and the availability of the vegetables to the growing population. Several insecticides came into limelight to reduce the effect of the pests but ultimately damaging the soil and human health due to their hygroscopic nature[58]. These insecticides are chemicals which are helpful in the beginning by killing the pests and ends up in danger by creating tolerance to the insects [59].

Although few innovations happened in reducing the damage caused by insects through biotechnology and Integrated Pest Management procedures[60]. In case of biotechnology there is considerable reduction in the pest activity and damage by killing the pests by genetic engineering and also releasing Bt crops, Eg. Potato, corn, maize, soybean etc. These Bt crops are not yet released due to some health related investigations and lack of permissions. The Integrated Pest Management was not very successful in some crop species[61].

By considering all the effects and problems associated with insect pest damage on the vegetable crops use of AMF was employed to reduce the damage caused by the pests. This use of bioinoculants was very successful in protecting the plants from damage and yield losses but not complete solution for pest eradication[62]. Also certain agricultural practices like crop rotation would effect the growth of bioinoculants in the soil by separating the link between the plants and the bioinoculants. Also certain practices like fertilizer application, tillage and pest management practices would limit the availability of the fungal inoculum in the soils[63].

Table 3: Use of amf against different pests:

\begin{tabular}{|l|l|l|}
\hline CROP & AMF SPECIES & PROTECTION AGAINST \\
\hline Wheat & T. harzianum & Stored grain pests \\
\hline Maize & T. viridae & Spotted stem borer \\
\hline Sorghum & T. virens & Ear head caterpillar \\
\hline Paddy & T. atroviridae & Stem borer and weevil \\
\hline Ground nut & T. harzianum & Gram pod borer \\
\hline Olive & G. intraradices & Verticillium wilt \\
\hline Papaya & G. manihotis & Root knot nematode \\
\hline Apple & G. versiforme & Pratylynchus nematode \\
\hline Strawberry & Glomus sps. + Bacillus sps. & $\begin{array}{l}\text { Severe wilt caused by } \\
\text { verticillium dahlea }\end{array}$ \\
\hline
\end{tabular}

The effects or losses caused by different pests like pod borers, stem borers, caterpillars and stored grain pests are greatly arrested with the use of different strains of amf fungi in cereals. 
Plants are known to possess certain self-defence tactics against insect pests like the production of gossypol, volatile compounds and nicotine which attack the pest and is useful up to a certain extent until the incidence of the pest is more[64]. But with the use of the fungal bioinoculants certain hormones like Jasmonic Acid was synthesized which was very helpful in protecting the plants against pests by killing the pests. Also these bioinoculants are known to reduce the feeding activity of plant chewing insects and also known to kill the sap sucking insects by indirectly promoting the production of jasmonic acid[65]. In some cases the use of AMF bioinoculants would increase the levels of tolerance against insect pests on plants whereas in few cases these fungal inoculants. The level; of amf applied to the plants would protect the plant from the negative effects caused by pests. Also amf makes several attempts to prevent the reduction of nutrients in plants so that they grow well even under severe pest conditions. Thus the use of amf is very helpful in maintaining the plant growth and development by reducing the maximum yield losses under pest incidence [66].

\section{Storage of amf Inoculum for Future Use:}

The fungal inoculum of amf that is produced using different techniques and treatments can be stored at room temperatures provided the conditions should be under control. These amf spores are very much adjustable to high heat and high cold conditions, but in few cases these spores tend to die or become inactive when the temperatures are miserable. Also the packaging of the produced spores should be done properly without any air gaps or space so that entry of other fungal inoculum can be restricted properly. If the package is not proper inoculum of other harmful fungi might enter the package and causes certain damage to the amf inoculum. Also, this entry of other fungal inoculum would interfere with the infectivity and growth of amf fungal spores. Also, when these amf spores along with fungal spores when applies to plants may create certain losses like disease growth or some pest attractions which would be harmful for both the plants and the amf inoculum. To avoid these losses proper packaging of the amf inoculum is very much necessary and important [67].

Storage of amf in soil mixtures can be saved up to few months under 30-40 degrees heat and cold temperature conditions provided the sample should be dry to avoid the quality and quantity losses. In some cases, poly vinyl lactic acid glycerol is added to the spores and dried properly and are allowed to store in plastic bags or boxes as permanent packets for further use. Also when spores are used for study purpose these are stored using glycerine or formaldehyde is added to the spores so that these spores can be stored properly. Such stored spores can be used for study purposes under microscope due tot heir clear nature with the addition of a drop of glycerine[68].

Some stained mycorrhiza are stained for observance under microscope and to conduct certain studies these spores are stored carefully using Melzers reagent. This reagent is added to the slides containing spores and covered carefully with a cover slip and these slides are stored properly in plastic containers. In some cases, the stained or unstained mycorrhizal roots are preserved in ethanol for longer time so that the viability of the spores can be maintained and these spores can be used o\for observation and further studies [69].

Although there are few methods on the storage of amf inoculum, these methods can be helpful to protect the fungi against degradation but has no effect on fungi multiplication. Storage of amf has been a major challenge to the producers because of the less shelf life of the fungus and its easy degradation. Several problems occurred due to storage of amf fungi as it has less 
demand compared to chemical fertilizers which is major problem. Several factors are associated when considered to the storage of the amf fungi which include production, carrier material and proper packaging. These factors play a major role in proper storage and transport of the fungi. Also, the date of expiry is very close to the date of manufacture i.e., less shelf life impacts the use of this amf fertilizers and also its storage [70].

The peat and granular composition have very less shelf life of about 6 months which is not enough for the storage which leads to quick expiry i.e., degradation of the spores and these formulations should be used within few months of packaging. Considering all the above problems and factors new liquid formulations came up providing maximum storage of about 2 years and more also the growth of fungal hyphae can be observed. These liquid formulations contain required nutrients for the fungal activity in the solution. Also, these liquid formulations are highly heat tolerant up to 45-55 degrees and can be stored in cool and dry places as much as under room temperatures which is a highly useful alternative towards proper storing of the amf fungal inoculum [71].

\section{Types of Fungal Formulations and Their Effectiveness:}

Different formulations of fungi are known to be present in the recent years after due to advancement of the technologies. Also several methods are available for the production , multiplication and storage of the fungal spores. As known the amf fungi has several advantages compared to chemical fertilizers their usage and production is gaining more importance. Now a days several formulations of fungi are available to make the easily available to the farmers and also to ease the usage of the inoculum [72]. Different formulations are advantageous over one another with their properties. The effectiveness of the amf fungal inoculum mainly depends upon its formulations. This area has gained importance recently due to the usage of different formulations on different plants or plant parts. These formulations of the fungal spores ultimately depend upon the carrier material. De3pending upon the type of the carrier material used, these can be divided into liquid and solid formulations [73].

Table 4: Different Fungal Formulations

\begin{tabular}{|l|l|l|}
\hline TYPE OF THE CARRIER & USES & DRAWBACKS \\
\hline COMPOST & Increases hyphal growth & $\begin{array}{l}\text { Reduction in mycorrhizal } \\
\text { rate }\end{array}$ \\
\hline GRANULES & $\begin{array}{l}\text { Effective under stresses and } \\
\text { easy storage }\end{array}$ & $\begin{array}{l}\text { Storage is difficult due to its } \\
\text { bulky nature }\end{array}$ \\
\hline CLAY & $\begin{array}{l}\text { Can be used in different } \\
\text { regions }\end{array}$ & $\begin{array}{l}\text { Effective only in the site of } \\
\text { application }\end{array}$ \\
\hline PEAT & Transport and storage is easy & $\begin{array}{l}\text { Other microbes may be } \\
\text { involved and not easily } \\
\text { available with pure amf } \\
\text { inoculum }\end{array}$ \\
\hline
\end{tabular}

Different forms of fungal inoculations are available based on the carrier material used. The type of carrier material mainly influence the usage of the fungus and its effectiveness. In some cases like clay type of formulation, the amf inoculum is effective at the site of inoculation which would be a major disadvantage for the entire field and the next growing season. Also in peat type of formulation amf spores are mixed with foreign spores and might be dangerous to 
the plant and the fungus itself. This presence of foreign spores would reduce the useful benefits of the amf spores and may lead to the degradation of the amf spores, it is also known that these foreign spores sometimes restrict the growth of amf fungal hyphae so that the population is gradually decreased. So out of all the composting type, granular type and newly emerged liquid tuype of formulations are quite useful to enhance the benefits of the amf fungi.

\section{Conclusion and future prospects}

As known the AMF species have gained much importance these days as they are easy to use, effective and highly beneficial. These amf inoculants are easy to isolate and produce, also the multiplication of these fungal inoculum is quite easy. Different fungal species are used as inoculations in different vegetables because of their benefits to the plants and the soils. Not only benefitting the plants and soils these fungi they themselves are benefitted due to symbiotic relationship with the plants by which the fungal colonies are developed and multiplied quickly which in turn would be helpful to the plant.

These amf species are used as an alternative sources for the harmful chemical fertilizers, insecticides and fungicides which would damage the soil and also human health due tot heir hygroscopic nature. These chemicals also kill the soil microbes and disturbs the soil texture. The nutrient contents in the soils are decreased gradually with the use of harmful chemicals. So to reduce these damages and also the damages caused by harmful pests and diseases in a natural and healthy way these amf fungi are used.

The use of amf is highly beneficial as the fungi promotes the uptake of nutrients from the soils by drawing the nutrients from the deeper layers of the soils. Certain important nutrients like $\mathrm{P}$, $\mathrm{Cu}, \mathrm{B}, \mathrm{S}, \mathrm{Al}$ and $\mathrm{Si}$ are available in the deeper layers of the soils. The amf fungi helps the plants to draw all the nutrients from the soils by increasing the nutrient content in the soils and also promoting the growth of roots in the plants, this way the plants and the soil both are equally benefitted by the use of amf species. In some cases these amf species are known to remove the harmful heavy metals from the soils with the help of their hyphae by sequestration or by heavy metals metabolization which is a very unique way of cleansing the soils from heavy metals that are very dangerous to human health. The growth of the plants are remarkably high due to the use of amf as these plants get many benefits from the use of amf species where the soil stability soil nutrition as well as weathering is maximum due to a unique fungal protein called glomulin. All these factors would help the plants to gain maximum benefits from the soils and aids in growth of the plants.

Not only in growth of the plants these amf are known to reduce the effects caused by harmful diseases and pests against plants. In many cases the plants that are infected with diseases and pests are known to show many symptoms, leading to loss of the yield and sometime causing the death of the plants. The use of amf species protects the plants by reducing the harmful effects caused by the pests and diseases. The amf reduces the symptoms in the plants up to a greater level so that the plants can cope up and continue to grow. Not only this sometimes amf assist in killing the root nematodes by arresting their growth so that it would be a greater advantage to the plant. Amf is known to restrict the growth of pathogens that cause root rots, wilts and damping off diseases by reducing the growth of pathogens in that area. By doing this the host plant relationship between the plants and harmful insects and pests is reduced and healthy growth of the plants is promoted. 
Apart from production and protection of the plants from harmful diseases and pests this amf is known to protect the plants from several abiotic stresses. Amf reduces cellular leakage and increases osmotic potential of the plants by promoting high photosynthetic rates under heat stress. Also amf is known to reduce the sodium uptake by the plants and maintains antioxidant production and accumulations of osmolytes under salinity stress. Whereas the abscisic acid content is highly reduced and increase in the leaf water potential along with photosynthesis rates was observed under drought stress.

Along with the benefits of the usage of amf fungi in crop production, against diseases and pests the production. There are several methods to store amf inoculum while used for studies and examining the spores. But in general, these fungal spores stored with chemicals would last for a few days or may stay alive but without any multiplication. Usually, the shelf life of the amf fungi is around six months and not more than that, which is major problem for the manufactures as they tend to face many loses. But certain new formulations like liquid formulations having nutrient solutions as carrier are very effective in storing the amf spores for about 2 years. These formulations are very effective in the growth of fungal hyphae. Along with the storage the formulations of the amf spores are very important as it depends upon the type of the carrier to which the fungal spores are attached. This carrier material allows the fungal hyphae to grow and expand deep into the soil providing nutrition to the plants and the fungus itself.

With the above benefits and uses amf is known to create many changes in cropping systems and improve the growth of the plants by reducing the harmful chemicals, pests and diseases and make wonders in growing vegetable crops which are a maximum source of fibre, minerals , vitamins and nutrients. Although the growth and mass multiplication of the amf needs to be improved well but the use of them is highly productive. The production of the amf in a simple way under controlled conditions also the storage of the amf under suitable conditions following all the necessary precautions needs to be improved in the future to utilise the benefits from the amf. Most importantly mass multiplication of these fungal colonies was given importance to improve the number of spores from a single hyphae. These are the main challenges that are to be concentrated in the near future as the utilizations of these fungal inoculums requires continuous supply.

Therefore maximum amount of amf fungi near the roots in the soil or on the surface of the soils would greatly effect the growth of the plants and soil conditions. Also more quantity of amf than required if present in or above the soil would not effect the plants in any negative way except for multiplying their own colonies. Thus in our review it was concluded that the use of amf in soils would effect the plants and soils in beneficial ways promoting healthy growth in plants and maintaining good health of the soils. Thus the use of these amf species not only effect the plants in a positive way but also helps the fungal colonies to multiply so that they occupy the inner layers of the soils which would be very beneficial even when crop rotation was done.

\section{References}

1. Tedersoo, L.; Sánchez-Ramírez, S.; Kõljalg, U.; Bahram, M.; Döring, M.; Schigel, D.S.; May, T.; Ryberg, M.; Abarenkov, K. High-level classification of the Fungi and a tool for evolutionary ecological analyses. Fungal Divers. 2018, 90, 135-159.

2. Spatafora, J.W.; Chang, Y.; Benny, G.L.; Lazarus, K.; Smith, M.E.; Berbee, M.L.; Bonito, G.; Corradi, N.; Grigoriev, I.V.; Gryganskyi, A.; et al. A phylum-level 
phylogenetic classification of zygomycete fungi based on genome-scale data. Mycologia 2016, 108, 1028-1046.

3. Johns, C.D. Agricultural Application of Mycorrhizal Fungi to Increase Crop Yields, Promote Soil Health and Combat Climate Change. Future Directions International. 2014. Available online: https://www.futuredirections.org.au/publication/agriculturalapplication-of-mycorrhizal-fungi-toincrease-crop-yields-promote-soil-health-andcombat-climate-change/ (accessed on 11 August 2020).

4. Nakmee, P.S.; Techapinyawat, S.; Ngamprasit, S. Comparative potentials of native arbuscular mycorrhizal fungi to improve nutrient uptake and biomass of Sorghum bicolor Linn. Agric. Nat. Resour. 2016, 50, 173-178.

5. Posta, K.; Duc, N.H. Benefits of Arbuscular Mycorrhizal Fungi Application to Crop Production under Water Scarcity. Drought Detect. Solut. 2020.

6. Bona, E.; Cantamessa, S.; Massa, N.; Manassero, P.; Marsano, F.; Copetta, A.; Lingua, G.; D’Agostino, G.; Gamalero, E.; Berta, G. Arbuscular mycorrhizal fungi and plant growth-promoting pseudomonads improve yield, quality and nutritional value of tomato: A field study. Mycorrhiza 2016, 27, 1-11.

7. Kim, S.J.; Eo, J.-K.; Lee, E.-H.; Park, H.; Eom, A.-H. Effects of Arbuscular Mycorrhizal Fungi and Soil Conditions on Crop Plant Growth. Mycobiology 2017, 45, 20-24.

8. Parihar, P.; Bora, M. Effect of mycorrhiza (Glomus mosseae) on morphological and biochemical properties of Ashwagandha (Withania somnifera) (L.) Dunal. J. Appl. Nat. Sci. 2018, 10, 1115-1123.

9. Al-Hmoud, G.; Al-Momany, A. Effect of Four Mycorrhizal Products on Squash Plant Growth and its Effect on Physiological Plant Elements. Adv. Crop. Sci. Technol. 2017, 5, 1-6.

10. Ban, D.; Ban, S.G.; Oplani'c, M.; Horvat, J.; Novak, B.; Žani'c, K.; Žnidařcǐc, D. Growth and Yield Response of Watermelon to in-row Plant Spacings and Mycorrhiza. Chil. J. Agric. Res. 2011, 71, 497-502.

11. Sharma M, Kaushik P, Chawade A. Frontiers in the Solicitation of Machine Learning Approaches in Vegetable Science Research. Sustainability. 2021;13(15):8600.

12. Sharma M, Kaushal R, Kaushik P, Ramakrishna S. Carbon Farming: Prospects and Challenges. Sustainability. 2021;13(19):11122.

13. Yadav V, Jha R, Kaushik P, others. Biochemical composition of potato biowaste of popular North Indian cultivars. Indian Journal of Biochemistry and Biophysics (IJBB). 2021;58(1):100-4.

14. Yadav VK, Jha RK, Kaushik P, Altalayan FH, Al Balawi T, Alam P. Traversing arbuscular mycorrhizal fungi and Pseudomonas fluorescens for carrot production under salinity. Saudi Journal of Biological Sciences. 2021;28(8):4217-23.

15. Yadav A, Saini I, Kaushik P, Ansari MA, Khan MR, Haq N. Effects of arbuscular mycorrhizal fungi and P-solubilizing Pseudomonas fluorescence (ATCC-17400) on morphological traits and mineral content of sesame. Saudi Journal of Biological Sciences. 2021;28(5):2649-54.

16. Sharma M, Saini I, Kaushik P, Al Dawsari MM, Al Balawi T, Alam P. Mycorrhizal Fungi and Pseudomonas fluorescens Application Reduces Root-Knot Nematode (Meloidogyne javanica) Infestation in Eggplant. Saudi Journal of Biological Sciences. 2021; 
17. Sharma M, Kaushik P. Vegetable Phytochemicals: An Update on Extraction and Analysis Techniques. Biocatalysis and Agricultural Biotechnology.

2021;102149.Sharma M, Kaushik P. Breeding for Root-Knot Nematode Resistance in Eggplant: Progress and Prospects. 2021;

18. Sharma M, Kaushik P. Biochemical Composition of Eggplant Fruits: A Review. Applied Sciences. 2021;11(15):7078.

19. Saini I, Kaushik P, Al-Huqail AA, Khan F, Siddiqui MH. Effect of the diverse combinations of useful microbes and chemical fertilizers on important traits of potato. Saudi Journal of Biological Sciences. 2021;28(5):2641-8.

20. Priyanka V, Kumar R, Dhaliwal I, Kaushik P. Germplasm Conservation: Instrumental in Agricultural Biodiversity_A Review. Sustainability. 2021;13(12):6743.

21. Malhi GS, Kaur M, Kaushik P. Impact of climate change on agriculture and its mitigation strategies: A review. Sustainability. 2021;13(3):1318.

22. Malhi GS, Kaur M, Kaushik P, Alyemeni MN, Alsahli AA, Ahmad P. Arbuscular mycorrhiza in combating abiotic stresses in vegetables: An eco-friendly approach. Saudi Journal of Biological Sciences. 2021;28(2):1465.

23. Kumar A, Kaushik P. Advances and Milestones of Radish Breeding: An Update. 2021

24. Kesh H, Kaushik P. Advances in melon (Cucumis melo L.) breeding: An update. Scientia Horticulturae. 2021;282:110045.

25. Kaushik P. Precision Vegetable Farming Technologies: An Update. 2021;

26. Gupta R, Kaushik P. Phyto-Potential of Allium cepa and Allium sativum. 2021;

27. Dhaliwal SK, Salaria P, Kaushik P. Pea Seed Proteins: A Nutritional and Nutraceutical Update. In: Grain and Seed Proteins Functionality. IntechOpen; 2021.

28. Brar NS, Sharma SP, Kaushik P. Visiting Potato from a Breeding Perspective: Accomplishments and Prospects. 2021;

29. Bijalwan P, Jeddi K, Saini I, Sharma M, Kaushik P, Hessini K. Mitigation of saline conditions in watermelon with mycorrhiza and silicon application. Saudi Journal of Biological Sciences. 2021;

30. Yadav VK, Singh R, Jha RK, Kaushik P, others. Biochemical variability of eggplant peel among Indian cultivars. Indian Journal of Biochemistry and Biophysics (IJBB). 2020;57(5):634-7.

31. Singh H, Sethi S, Kaushik P, Fulford A. Grafting vegetables for mitigating environmental stresses under climate change: a review. Journal of Water and Climate Change. 2020;11(4):1784-97.

32. Sharma I, Dhaliwal IK, Bijalwan P, Yadav VK, Kaushik P. A Brief Perspective on Lost Traditional Grains and Food Habits of Indians. Int J Curr Microbiol App Sci. 2020;9(12):2295-305.

33. Saini I, Yadav VK, Aggarwal A, Kaushik P, others. Effect of superphosphate, urea and bioinoculants on Zinnia elegans Jacq. Indian Journal of Experimental Biology (IJEB). 2020;58(10):730-7.

34. Saini DK, Devi P, Kaushik P. Advances in genomic interventions for wheat biofortification: a review. Agronomy. 2020;10(1):62.

35. Kumar P, Kaushik P. Evaluation of genetic diversity in cultivated and exotic germplasm sources of Faba Bean using important morphological traits. BioRxiv. 2020; 
36. Kumar A, Sharma V, Jain BT, Kaushik P. Heterosis breeding in eggplant (Solanum melongena L.): Gains and provocations. Plants. 2020;9(3):403.

37. Kesh H, Kaushik P. Visiting Bitter Gourd (Momordica charantia) from a Breeding Perspective: A Review. 2020;

38. Kesh H, Kaushik P. Impact of Marker Assisted Breeding for Bacterial Blight Resistance in Rice: A Review. Plant Pathology Journal. 2020;19(2):151-16.

39. Kaushik P, Sandhu OS, Brar NS, Kumar V, Malhi GS, Kesh H, et al. Soil Metagenomics: Prospects and Challenges. In: Mycorrhizal Fungi-Utilization in Agriculture and Industry. IntechOpen; 2020.

40. Kaushik P. Classification of Indian states and union territories based on their Soil macronutrient and organic carbon profiles. bioRxiv. 2020;

41. Kaushik P. Characterization of Cultivated Eggplant and its Wild Relatives Based on Important Fruit Biochemical Traits. Pakistan Journal of Biological Sciences: PJBS. 2020;23(9):1220-6.

42. Dhaliwal SK, Talukdar A, Gautam A, Sharma P, Sharma V, Kaushik P. Developments and prospects in imperative underexploited vegetable legumes breeding: a review. International Journal of Molecular Sciences. 2020;21(24):9615.

43. Brar NS, Saini DK, Kaushik P, Chauhan J, Kamboj NK. Directing for higher seed production in vegetables. Agronomy-Climate Change \& Food Security. 2020;55.

44. Brar NS, Kumar T, Kaushik P. Integration of technologies under climate change for profitability in vegetable cultivation: an outlook. 2020;

45. Sunilkumar M. Genetic divergence in exotic tomato (Solanum lycopersicum L.) genotypes cultivated in southern India. Journal of Pharmacognosy and Phytochemistry. 2019;8(4):710-2.

46. Saini I, Aggarwal A, Kaushik P. Inoculation with mycorrhizal fungi and other microbes to improve the morpho-physiological and floral traits of Gazania rigens (L.) Gaertn. Agriculture. 2019;9(3):51.

47. Saini I, Aggarwal A, Kaushik P. Influence of biostimulants on important traits of Zinnia elegans Jacq. under open field conditions. International Journal of Agronomy. 2019;2019.

48. Kaushik P, Saini DK. Silicon as a vegetable crops modulator-A review. Plants. 2019;8(6):148.

49. Brar NS, Kaushik P, Dudi BS. Assessment of natural ageing related physiobiochemical changes in onion seed. Agriculture. 2019;9(8):163.

50. Sharma M, Kaushik P, Chaturvedi P. Enumeration, antagonism and enzymatic activities of microorganisms isolated from railway station soil. bioRxiv. 2018;454595.

51. Jakhar P, Yogesh O, Janu A, Kaushik P. Effect of different modes of pollination on quantitative and qualitative parameters of radish seed crop. Trends in Biosci. 2014;7:4041-4.

52. Kumar A, Kumar P, Kumar A, others. Study of Various Development Media for Standardization of Immature Embryo Culture in Capsicum annuum L. Biosciences. 2013;237.

53. Cotton, T.E.A. Arbuscular mycorrhizal fungal communities and global change: An uncertain future. FEMS Microbiol. Ecol. 2018, 94, 11. 
54. Bennett, A.E.; Classen, A. Climate change influences mycorrhizal fungal-plant interactions, but conclusions are limited by geographical study bias. Ecologies 2020, 101, e02978.

55. Tedersoo, L.; Sánchez-Ramírez, S.; Kõljalg, U.; Bahram, M.; Döring, M.; Schigel, D.S.; May, T.; Ryberg, M.; Abarenkov, K. High-level classification of the Fungi and a tool for evolutionary ecological analyses. Fungal Divers. 2018, 90, 135-159.

56. Spatafora, J.W.; Chang, Y.; Benny, G.L.; Lazarus, K.; Smith, M.E.; Berbee, M.L.; Bonito, G.; Corradi, N.; Grigoriev, I.V.; Gryganskyi, A.; et al. A phylum-level phylogenetic classification of zygomycete fungi based on genome-scale data. Mycologia 2016, 108, 1028-1046.

57. Posta, K.; Duc, N.H. Benefits of Arbuscular Mycorrhizal Fungi Application to Crop Production under Water Scarcity. Drought Detect. Solut. 2020.

58. Parihar, P.; Bora, M. Effect of mycorrhiza (Glomus mosseae) on morphological and biochemical properties of Ashwagandha (Withania somnifera) (L.) Dunal. J. Appl. Nat. Sci. 2018, 10, 1115-1123.

59. Bi Y, Zhang Y, Zou H (2018) Plant growth and their root development after inoculation of arbuscular mycorrhizal fungi in coal mine subsided areas. Int J Coal Sci Technol 5:47-53. https:// doi.org/10.1007/s40789-018-0201-x

60. Chen Y, Martin C, Mabola JCF et al (2019) Efects of Host plants reared under elevated $\mathrm{CO} 2$ concentrations on the foraging behavior of diferent stages of corn leaf aphids Rhopalosiphum maidis. Insects 10:182.

https://doi.org/10.3390/insects10060182

61. Formenti L, Rasmann S (2019) Mycorrhizal fungi enhance resistance to herbivores in tomato plants with reduced jasmonic acid production. Agronomy 9:131. https://doi.org/10.3390/agronomy9030131

62. Garzo E, Rizzo E, Fereres A, Gomez SK (2018) High levels of arbuscular mycorrhizal fungus colonization on Medicago truncatula reduces plant suitability as a host for pea aphids (Acyrthosiphon pisum). Insect Sci 27:99-112. https://doi. org/10.1111/1744-7917.12631

63. Hariprasanna K, Patil JV (2015) Sorghum: origin, classification, biology and improvement. Sorghum Mol Breed. https://doi. org/10.1007/978-81-322-2422-8_1

64. Mukherjee D (2017) Microorganisms: role for crop production and its interface with soil agroecosystem. Plant-Microbe Interact AgroEcol Perspect.

https://doi.org/10.1007/978-981-10-5813-4 17

65. Hill EM, Robinson LA, Abdul-Sada A et al (2018) Arbuscular mycorrhizal fungi and plant chemical defence: efects of colonisation on aboveground and belowground metabolomes. J Chem Ecol 44:198-208. https://doi.org/10.1007/s10886-017-0921-1

66. Murrell EG, Ray S, Lemmon ME et al (2019) Cover crop species afect mycorrhizaemediated nutrient uptake and pest resistance in maize. Renew Agric Food Syst. https://doi.org/10.1017/s1742 170519000061

67. Kariyat RR, Gafoor I, Sattar S et al (2019) Sorghum 3-deoxyanthocyanidin favonoids confer resistance against corn leaf aphid. J Chem Ecol 45:502-514. https://doi.org/10.1007/s10886-019-01062-8

68. Venkateswaran K, Elangovan M, Sivaraj N (2019) Origin, domestication and difusion of Sorghum bicolor. Breed Sorghum Divers End Uses. https://doi.org/10.1016/b978$\underline{0-08-101879-8.00002-4}$ 
69. Bio-FITProject. Biofertilizers Market Size. Available online: https://www.biofit.eu/hu/q5/lo12-bio-fertilizers-market-size? showall=1 (accessed on 29 December 2020).

70. Makarov, M. The Role of Mycorrhiza in Transformation of Nitrogen Compounds in Soil and Nitrogen Nutrition of Plants: A Review. Eurasian Soil Sci. 2019, 52, $193-$ 205.

71. Owen, D.; Williams, A.P.; Griffith, G.W.; Withers, P.J.A. Use of commercial bioinoculants to increase agricultural production through improved phosphrous acquisition. Appl. Soil Ecol. 2015, 86, 41-54.

72. Wagg, C.; Barendregt, C.; Jansa, J.; Van der Heijden, M. Complementarity in both plant and mycorrhizal fungal communities are not necessarily increased by diversity in the other. J. Ecol. 2015, 103.

73. Colonna, E.; Rouphael, Y.; Pascale, S.D.; Barbieri, G. Effects of mycorrhiza and plant growth promoting rhizobacteria on yield and quality of artichoke. Acta Horticult. 2016, 1147, 43-50. 